\title{
MÉTODO EXPEDITO DE ANÁLISE QUALITATIVA DA ARBORIZAÇÃO DA PRAÇA EUFRÁSIO CORREIA, CURITIBA- PR
}

\author{
EXPEDITO METHOD FOR THE AFFORESTATION'S QUALITATIVE ANALYSIS OF \\ EURÁSIO CORREIA SQUARE, CURITIBA - PR
}

Italo Filippi Teixeira ${ }^{1}$, Jéssika dos Santos Nunes ${ }^{2}$

\section{RESUMO}

Este estudo teve como objetivo avaliar a atual situação da arborização na Praça Eufrásio Correia, CuritibaPR, através do Método Expedito de Análise Qualitativa visando subsidiar o manejo da vegetação deste espaço livre público. O estudo foi realizado mediante a aplicação do referido método supracitado, o qual utiliza a avaliação com parâmetros variáveis relacionados à qualidade da copa, qualidade de poda, deterioração do tronco, fitossanidade, presença de hemiparasitas, distância para construções, distância para calçada ou meio fio, distância para outra árvore, raízes superficiais, presença de solo exposto no entorno do exemplar, altura da bifurcação, deterioração do tronco, inclinação do tronco, contato com a fiação e compatibilidade com o meio. Essas variáveis são numericamente pontuadas e comparadas com pontuações tabeladas, sendo possível classificar cada árvore em excelente, boa, regular ou péssima. Foram avaliadas 89 árvores de diferentes espécies. De acordo com os resultados, 15 árvores foram classificadas em excelentes, $45 \mathrm{em}$ boas, $24 \mathrm{em}$ regulares e 5 se enquadraram em péssima. A maioria das árvores em condição regular necessitam da aplicação de um manejo adequado para estimular suas atividades fisiológicas e recuperar o vigor. No entanto é importante salientar que esta metodologia gera informações de caráter empírico podendo limitar a sua eficiência.

Palavras-chave: Espaço livre público, avaliação, manejo

\section{ABSTRACT}

The objective of this study was to evaluate the current situation of trees in Eufrásio Correia Square, CuritibaPR, through the Expedito Method of Qualitative Analysis aiming to subsidize the management of the vegetation of this public space. The study was conducted by applying the above mentioned method, which uses the evaluation with variable parameters related to crown quality, pruning quality, trunk deterioration, phytosanitary condition, presence of hemiparasites, distance to buildings, distance to sidewalk or distance to another tree, shallow roots, presence of exposed soil around the specimen, bifurcation height, trunk inclination, contact with aerial wires and compatibility with the environment. These variables are numerically punctuated and compared with tabulated scores, being possible to classify each tree as excellent, good, regular or poor. A total of 89 trees of different species were evaluated. According to the results, 15 trees were classified as excellent, 45 were good, 24 were regular, and 5 were in poor condition. The majority of trees in regular condition need proper management to stimulate their physiological activities and regain vigor. However, it is important to note that this methodology generates empirical information and may limit its efficiency.

Keywords: Public open space, evaluation, management.

Recebido em 06.06.2019 e aceito em 30.08.2019

1 Engenheiro Florestal.Doutor em Engenharia Florestal. Professor Universidade Federal do Pampa Campus São Gabriel.São Gabriel/RS. Email: ítalo.filippi@gmail.com

2 Engenheira Florestal. Santana do Livramento/RS. Email: jessnunes104@gmail.com 


\section{INTRODUÇÃO}

Conforme Salbitano et al. (2017), todas as cidades compartilham de uma estrutura física similar, que compreende a infra-estrutura "cinza" (p.ex., edificações residenciais e industriais, ruas, serviços e estacionamentos), a infra-estrutura "azul" (p.ex., rios, lagos e canais hídricos) e a infra-estrutura "verde" (p.ex., árvores, arbustos e gramados nos parques, bosques, jardins e ruas). A fim de remodelar ou construir cidades capazes de responder aos desafios urbanos, é fundamental otimizar as interações entre estes elementos.

Constituindo essa infra-estrutura verde têm-se as árvores que em conjunto com arbustos e outras plantas menores caracterizam os espaços da cidade por suas formas, cores e modo de agrupamento. Constituem-se em elementos de composição e de desenho urbano ao contribuir para organizar, definir e até delimitar esses espaços (MASCARÓ; MASCARÓ, 2010).

A tendência da arborização urbana ser uma solução geral para muitos dos problemas urbanos, principalmente ambientais e estéticos é difundido em muitos trabalhos técnicos. São necessários mais parques para as cidades, calçadas mais bem sombreadas ou criar mais contrastes entre o concreto e o natural, tornando o ambiente urbano visualmente mais colorido através das árvores consorciadas com os outros estratos (arbustos, herbáceas, forrações e palmeiras).

Esta vegetação foi gradativamente crescendo, porém nem sempre com uma previsão de planejamento e manejo adequado, conforme comenta Sampaio et al. (2010). Com isso, existe um aumento visível da queda de árvores, assim como, uma perda de vitalidade das mesmas, pois grande parte se encontra em idade avançada e sobrecarregada pelo estresse provindo do ambiente urbano (podas constantes, injúrias mecânicas, poluição atmosférica, luz excessiva, etc).

Conforme Brazolin et al. (2014), os critérios para avaliar estas árvores tem sido basicamente a avaliação visual e o manejo de árvores de risco como parte do processo de gestão da arborização urbana e do licenciamento ambiental nas prefeituras municipais. Ocorre uma falta de critérios, segundo Gonçalves, Stringheta e Coelho (2007), para avaliação e a tomada de decisão para supressão de árvores urbanas com potencial de queda ou que ofereçam riscos, pois não envolvem apenas patrimônio material, mas principalmente a vidas humanas.

Este trabalho teve como objetivo avaliar a atual situação da arborização na Praça Eufrásio Correia, Curitiba-PR, usando o Método Expedito de Análise Qualitativa, buscando subsidiar o manejo da vegetação deste espaço livre público. 


\section{MATERIAL E MÉTODOS}

\section{Área do estudo}

Curitiba, capital do Paraná, está a 934,6 metros de altitude e possui relevo levemente ondulado, com colinas suavemente arredondadas, dando-lhe uma fisionomia relativamente regular (IPPUC, 2013). Segundo classificação climática de Köppen, Curitiba localiza-se em região climática do tipo $\mathrm{Cfb}$, com clima temperado (ou subtropical) úmido, mesotérmico, sem estação seca, com verões frescos, e invernos com geadas freqüentes e ocasionais precipitações de neve. De acordo com IPPUC (2011), os ventos predominantes são na direção NE-SO, com velocidade média anual de $2,1 \mathrm{~m} / \mathrm{s}$. As médias de temperatura são de $19,7^{\circ} \mathrm{C}$ no verão e $13,4^{\circ} \mathrm{C}$ no inverno. A precipitação média anual é de 1.419,91 mm, com um período de estiagem entre o outono e o inverno.

Foi selecionada a Praça Eufrásio Correia ou Praça da Estação, localizada no centro de Curitiba-PR, entre as Ruas Barão do Rio Branco com Avenida 7 de Setembro. A mesma possui aproximadamente $7000 \mathrm{~m}^{2}$ e um fluxo intenso de pedestres devido a sua localização no entorno da câmara municipal de vereadores, hotéis, comércios e restaurantes caracterizando assim uma área potencial para esta pesquisa.

\section{Aplicação do Método Expedito de Análise Qualitativa}

Esta proposta de método expedito baseia-se na classificação subjetiva de cada exemplar arbóreo, com objetivo de subsidiar decisões futuras de manejo, utilizando-se 15 parâmetros para avaliação com as respectivas categorizações de notas:

- Qualidade da copa - refere-se à exuberância da copa, ritmo de brotação, coloração das folhas, epicormia e sazonalidade de acordo com a análise fitossociológica.

Tabela 1. Categorização de nota e qualificação da copa da espécie vegetal avaliada Table 1. Categorization of grades and crown qualification of the evaluated plant species

\begin{tabular}{cl}
\hline NOTA & \multicolumn{1}{c}{ QUALIFICAÇÃO } \\
\hline 1 & $\begin{array}{l}\text { Copa com a presença de galhos mortos e danificados devido a podas anteriores, acidentes } \\
\text { e eventos climáticos }\end{array}$ \\
\hline 2 & $\begin{array}{l}\text { Copa com brotações epicórmicas com ritmo adequado e/ou em período sazonal com } \\
\text { ausência de folhas. }\end{array}$ \\
\hline 3 & Copa exuberante, robusta e sadia. \\
\hline
\end{tabular}

-.Qualidade da poda - avalia os resquícios deixados por podas anteriores na planta e o quanto esses resquícios influenciaram na vida da árvore. 
Tabela 2. Categorização de nota e qualificação da poda da espécie vegetal avaliada

Table 2. Categorization of grades and pruning qualification of the evaluated plant species

\begin{tabular}{cl}
\hline NOTA & \multicolumn{1}{c}{ QUALIFICAÇÃO } \\
\hline 1 & Presença de poda drástica com tocos residuais, linha de corte irregular e lascas. \\
\hline 2 & $\begin{array}{l}\text { Presença de má cicatrização como resultado de podas anteriores, mas com intervenção e } \\
\text { manejo pode-se resolver. }\end{array}$ \\
\hline 3 & Podas anteriores com boa cicatrização e que o formato da espécie não foi descaracterizado. \\
\hline
\end{tabular}

- Equilíbrio da árvore - analisa a árvore como um todo, comparando condição de copa e tronco como resultados de intervenções sofridas anteriormente.

Tabela 3. Categorização de nota e qualificação do equilíbrio da espécie vegetal avaliada

Table 3. Categorization of grades and balance qualification of the evaluated plant species

\begin{tabular}{cl}
\hline NOTA & QUALIFICAÇÃO \\
\hline 1 & $\begin{array}{l}\text { Copa e tronco não condizem com as características da espécie na arborização urbana } \\
\text { devido a poda drásticas, de rebaixamento de copa e/ou liberação de fiação. }\end{array}$ \\
\hline 2 & $\begin{array}{l}\text { Copa ou tronco fora do padrão esperado de ocorrência na arborização urbana, com manejo } \\
\text { e intervenção pode solucionar. }\end{array}$ \\
\hline 3 & Copa e tronco de acordo com as características da espécie implantada na arborização. \\
\hline
\end{tabular}

- Contato com a fiação - analisa a urgência e/ou a necessidade de intervenção.

Tabela 4. Categorização de nota e qualificação do contato com a fiação elétrica da espécie vegetal avaliada

Table 4. Categorization of grades and contact with the electrical wiring qualification of the evaluated plant species

\begin{tabular}{cl}
\hline NOTA & \multicolumn{1}{c}{ QUALIFICAÇÃO } \\
\hline 1 & Exemplar arbóreo em contato com a fiação. \\
\hline 2 & Exemplar arbóreo com potencial de contato com a fiação. \\
\hline 3 & Exemplar arbóreo sem possibilidade de contato com a fiação elétrica. \\
\hline
\end{tabular}

- Deterioração do tronco - evidencia o tronco e sua atual situação, pois além de ser parte importante para a sustentação da planta como estrutura física é um local de fácil contaminação por patógenos.

Tabela 5. Categorização de nota e qualificação da deterioração do tronco da espécie vegetal avaliada Table 5. Categorization of grades and deterioration of the trunk qualification of the evaluated plant species

\begin{tabular}{cl}
\hline NOTA & \multicolumn{1}{c}{ QUALIFICAÇÃO } \\
\hline 1 & $\begin{array}{l}\text { Tronco possui cavidades e lesões que facilitam entrada de patógenos e dificultam a } \\
\text { estabilidade da árvore. }\end{array}$ \\
\hline 2 & Tronco injuriado devido acidentes e lascas por podas antigas. \\
\hline 3 & Tronco íntegro que garante estabilidade para a árvore. \\
\hline
\end{tabular}

- Características da bifurcação - a altura da bifurcação deve ser considerada em qualquer avaliação de qualidade e risco de queda, pois é um fator que influencia e potencializa riscos de queda de galhos e até da árvore. De acordo com a altura da bifurcação pode-se planejar um manejo diferenciado, especializado para aquele indivíduo. 
Tabela 6. Categorização de nota e qualificação das características da bifurcação da espécie vegetal avaliada

Table 6. Categorization of grades and characteristics of the bifurcation qualification of the evaluated vegetal species

\begin{tabular}{cl}
\hline NOTA & \multicolumn{1}{c}{ QUALIFICAÇÃO } \\
\hline 1 & $\begin{array}{l}\text { Bifurcação abaixo do DAP caracterizando maiores chances de queda, pois cria um ponto de } \\
\text { acumulo de umidade. }\end{array}$ \\
\hline 2 & Bifurcação acima do DAP que garante maior estabilidade. \\
\hline 3 & Sem bifurcação que possibilita copa ampla e menor índice de intervenções e podas. \\
\hline
\end{tabular}

- Inclinação do tronco - avalia a possibilidade de uma intervenção e possibilita uma análise do espaço que a planta ocupa, porém levando-se em conta que algumas espécies possuem inclinação natural e também reagem mal à podas.

Tabela 7. Categorização de nota e qualificação da inclinação do tronco da espécie vegetal avaliada Table 7. Categorization of grades and trunk inclination qualification of the evaluated plant species

\begin{tabular}{cl}
\hline NOTA & \multicolumn{1}{c}{ QUALIFICAÇÃO } \\
\hline 1 & Tronco que apresenta risco de queda aparente. \\
\hline 2 & Tronco com inclinação aceitável para o local. \\
\hline 3 & Tronco de acordo com o padrão da espécie \\
\hline
\end{tabular}

- Fitossanidade - a presença de agentes fitossanitários é avaliada devido ao seu impacto negativo que causa no crescimento e desenvolvimento da árvore além de causar fragilidade a planta.

Tabela 8. Categorização de nota e qualificação da fitossanidade da espécie vegetal avaliada Table 8. Categorization of grades and phytosanitary condition qualification evaluated plant species

\begin{tabular}{cl}
\hline NOTA & QUALIFICAÇÃO \\
\hline 1 & Presença de agentes fitossanitários como pulgão, cochonilha, cupim e exsudação. \\
\hline 3 & Planta sadia, sem infestação.
\end{tabular}

- Presença de hemiparasitas - esse fator valia a presença e a proporção das "ervas de passarinho" na copa do exemplar arbóreo.

Tabela 9. Categorização de nota e qualificação da presença de hemiparasitas da espécie vegetal avaliada

Table 9. Categorization of grades and presence of hemiparasites qualification of the evaluated plant species

\begin{tabular}{cl}
\hline NOTA & \multicolumn{1}{c}{ QUALIFICAÇÃO } \\
\hline 1 & $>$ ou $=75 \%$ da copa ocupada, tendência de futura supressão; \\
\hline 2 & Entre $74 \%$ e $26 \%$ da copa ocupada, nesse caso intervenção ainda é válida; \\
\hline 3 & $<25 \%$ da copa ocupada - fácil manejo
\end{tabular}

- Afloramento de raízes - é possível ter uma percepção da resistência mecânica do solo e o quão superficial está a raiz. Em caso de raízes enoveladas superficiais observar-se o diâmetro das mesmas e a potencialidade de comprometimento para o exemplar. 
Tabela 10. Categorização de nota e qualificação das características de raízes superficiais da espécie vegetal avaliada

Table 10. Categorization of grades and characteristics of the roots' qualification of the evaluated vegetal species

\begin{tabular}{cl}
\hline NOTA & \multicolumn{1}{c}{ QUALIFICAÇÃO } \\
\hline 1 & Apresenta afloramento de raízes e/ou enovelamento \\
\hline 3 & Não apresenta afloramento de raízes \\
\hline
\end{tabular}

- Solo exposto - através da avaliação desse parâmetro na análise do local do exemplar, obtemse um melhor diagnóstico sobre exposição de raízes e do colo da planta.

Tabela 11. Categorização de nota e qualificação do solo exposto da espécie vegetal avaliada

Table 11. Categorization of grades and exposed soil qualification of the evaluated plant species

\begin{tabular}{cl}
\hline NOTA & \multicolumn{1}{c}{ QUALIFICAÇÃO } \\
\hline 1 & $\begin{array}{l}\text { Apresenta solo exposto na projeção da copa do exemplar, que aumenta a lixiviação do solo, } \\
\text { diminui a aeração e cria uma camada superficial de solo diminuindo a absorção de água pelo } \\
\text { mesmo. }\end{array}$ \\
\hline 3 & Solo coberto e protegido. \\
\hline
\end{tabular}

- Compatibilidade com o meio - avalia-se a planta como um todo interagindo com o meio e suas estruturas.

Tabela 12. Categorização de nota e qualificação da compatibilidade com o meio da espécie vegetal avaliada

Table 12. Categorization of grades and environment compatibility classification of the evaluated plant species

\begin{tabular}{cl}
\hline NOTA & \multicolumn{1}{c}{ QUALIFICAÇÃO } \\
\hline 1 & $\begin{array}{l}\text { Indivíduo arbóreo não está compatível com o meio devido a podas irregulares, espécie, porte } \\
\text { e local inadequados. }\end{array}$ \\
\hline 2 & $\begin{array}{l}\text { Indivíduo arbóreo que pode tornar-se compatível com o meio se realizadas intervenções e } \\
\text { manejos adequados. }\end{array}$ \\
\hline 3 & Indivíduo arbóreo que se encontra compatível com o meio.
\end{tabular}

- Distância para construções e edificações - observa-se o espaço livre de crescimento de raízes e copa em relação a construções e também o planejamento de possíveis intervenções.

Tabela 13. Categorização de nota e qualificação da distância para construções e edificações da espécie vegetal avaliada

Table 13. Categorization of grades and distance to buildings qualification of the evaluated plant species

\begin{tabular}{cl}
\hline NOTA & \multicolumn{1}{c}{ QUALIFICAÇÃO } \\
\hline 1 & Distância <2 metros para construções ou edificações \\
\hline 2 & Distância de 2 a 5 metros de construções. \\
\hline 3 & Distância maior que 5 metros de construções ou edificações. \\
\hline
\end{tabular}

- Distância da árvore mais próxima - observa-se o espaço livre de crescimento de raízes e copa em relação a árvore mais próxima e também o planejamento de possíveis intervenções. 
Tabela 14. Categorização de nota e qualificação da distância entre árvores da espécie vegetal avaliada Table 14. Categorization of grades and distance between trees qualification of the evaluated plant species
NOTA
1 Distância $<2$ metros para espécie mais próxima
2 Distância de 2 a 5 metros para espécie mais próxima
3 Distância maior que 5 metros para espécie mais próxima

- Distância da calçada ou meio-fio - avalia-se o espaço livre de crescimento de raízes em relação aos limites de calçada e meio fio, e também o planejamento de possíveis intervenções.

Tabela 15. Categorização de nota e qualificação da distância para calçada ou meio fio da espécie vegetal avaliada

Table 15. Categorization of grades and distance to sidewalk qualification of the evaluated plant species

\begin{tabular}{cl}
\hline NOTA & QUALIFICAÇÃO \\
\hline 1 & Distância <2 metros para calçada ou meio fio \\
\hline 2 & Distância de 2 a 5 metros para calçada ou meio fio \\
\hline 3 & Distância maior que 5 metros para calçadas ou meio fio \\
\hline
\end{tabular}

Após a avaliação baseada nestes parâmetros e o preenchimento da ficha técnica para cada exemplar, a nota é somada e o resultado encaixado em quatro categorias: excelente, boa, regular ou péssima conforme de acordo com a Tabela 16. As classificações tem suas pontuações como resultado dos somatórios dos pontos obtidos em cada item. A amplitude das classes baseia-se na nota mínima e máxima assim como intervalos estabelecidos buscando-se ampliar as possibilidades de classificações em no mínimo 4 classes.

Tabela 16. Ranqueamento da pontuação e respectiva classificação da árvore avaliada

Table 16. Ranking of the evaluated tree and its classification

\begin{tabular}{cc}
\hline SOMATÓRIO DA PONTUAÇÃO INDIVIDUAL & CLASSIFICAÇÃO \\
\hline $15-25$ & PÉSSIMA \\
\hline $26-30$ & REGULAR \\
\hline $31-38$ & BOA \\
\hline $39-45$ & EXCELENTE
\end{tabular}

\section{RESULTADOS E DISCUSSÃO}

O censo realizado na praça Eufrásio Correia, Curitiba-PR, indicou a existência de 89 exemplares arbóreos, objeto de avaliação do Método Expedito de Análise Qualitativa, incluindo árvores adultas e palmeiras, sendo 3 árvores tombadas como patrimônio histórico-cultural de Curitiba-PR, sendo 2 exemplares de Phoenix dactilyfera L. (Tamareira) e 1 de Cedrela fissilis Vell. (Cedro-rosa).

Quanto a qualidade da copa (figura 1), a maioria das espécies avaliadas apresentaram uma copa vigorosa caracterizando a vegetação deste espaço livre público como saudável, uma vez que a robustez da copa da árvore, que é o reflexo do desenvolvimento dos exemplares. 
Resultado semelhante foi obtido por Sampaio et al. (2010) na cidade de Nova Olímpia-SP, onde, de uma população de 2230 exemplares arbóreos adultos inventariados, 72,35\% não apresentaram sinais de depreciação de suas copas sendo considerado um bom indicativo, pois a copa é a região mais ampla e bem desenvolvida na maioria das árvores urbanas, e também a mais utilizada pela fauna, aves principalmente, e é onde acontecem às principais atividades fenológicas das plantas.

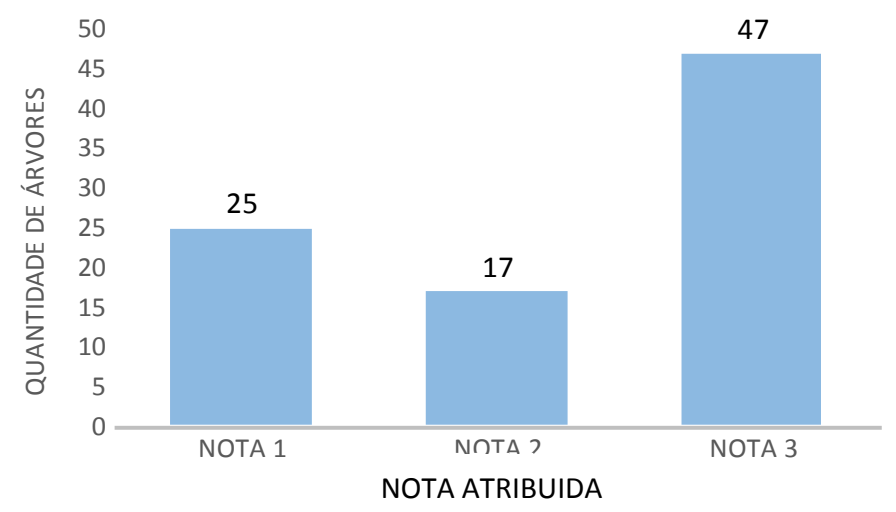

Figura 1. Distribuição dos 89 exemplares arbóreos nas categorias referentes a qualidade da copa

Figure 1. Distribution of the 89 tree species in the categories referring to the quality of the crown

De um total de 89 árvores observa-se por meio da figura 2 que a maioria das árvores apresentou a nota 3 quanto à qualidade da poda, ou seja, houve poda porém sem a desconfiguração da copa das espécies. A poda é uma prática corriqueira como comenta Martins, Andrade e De Angelis (2010) que desenvolveram um estudo em Luiziana-PR, nas 1540 árvores da área central, onde analisaram a relação entre podas e aspectos fitossanitários e identificaram que $61 \%$ das mesmas tinham sinais visíveis de poda.

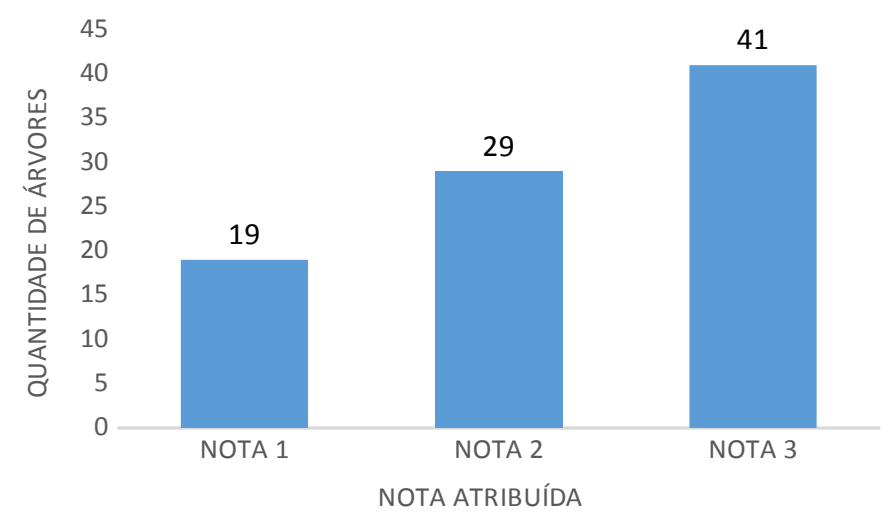

Figura 2. Distribuição dos 89 exemplares arbóreos nas categorias referentes a qualidade da poda Figure 2. Distribution of the 89 tree species in the categories referring to quality of pruning

Os resultados apresentados na figura 3 demonstram que, quanto ao equilíbrio da árvore, a maioria das espécies avaliadas apresenta um desequilíbrio na copa ou no tronco que não 
condiz com a espécie e com o meio, o que acarreta maior risco de queda de galhos ou tombamento da árvore. Kontogianni, Tsitsoni e Goudelis (2011) ao avaliarem quatro espécies florestais, na arborização de ruas de Thessaloniki, Grécia, propuseram a criação de um índice empírico que correlaciona a estabilidade das árvores com características silviculturais como o raio de projeção da copa, o índice de assimetria da copa e a altura da árvore. Esta concepção partiu do princípio de que quando as árvores estão sadias as características silviculturais das árvores assumem maior importância na estabilidade das mesmas.

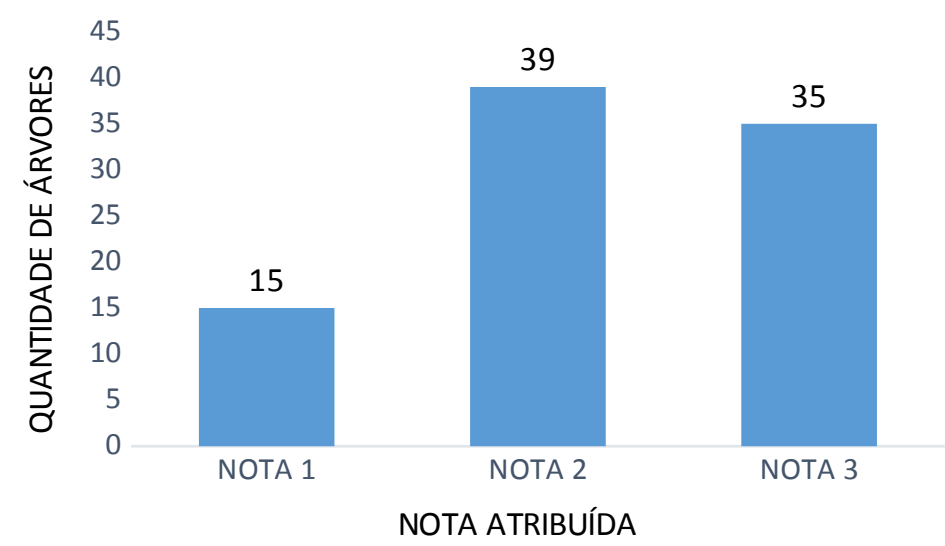

Figura 3. Distribuição dos 89 exemplares arbóreos nas categorias referentes ao equilíbrio da árvore Figure 3. Distribution of the 89 species in the categories for the tree balance

Por isso o equilíbrio da árvore é um fator determinante para a perspectiva de vida da planta e segurança da população, tornando essencial sua análise. Esse resultado é semelhante ao estudo feito no Mato Grosso do Sul por Pelegrim et al. (2012), onde verificou que, dos 1228 exemplares avaliados, $88,4 \%$ desses apresentaram uma copa equilibrada e $82,90 \%$ apresentaram o caule equilibrado das árvores do bairro Flamboyant em Chapadão do Sul.

Santos et al. (2015) também realizaram um estudo semelhante na cidade de Aracaju SE, em 25 vias, onde citaram que o equilíbrio geral define a boa relação do caule e copa das árvores. Nestas vias $42 \%$ dos indivíduos não apresentaram esse equilíbrio, em virtude de vários fatores como: consecutivas podas mal executadas, impedimentos físicos ao seu crescimento natural, ou ainda, devido a ação dos ventos costeiros predominantes.

Como resultados desse parâmetro na Praça Eufrásio Correia não foram diagnosticados indivíduos arbóreos em contato com a fiação e somente um com potencial de contato com a fiação (figura 4), o que está dentro da normalidade visto que a fiação passa no seu entorno e as podas para liberação de fiação estão em dia. 


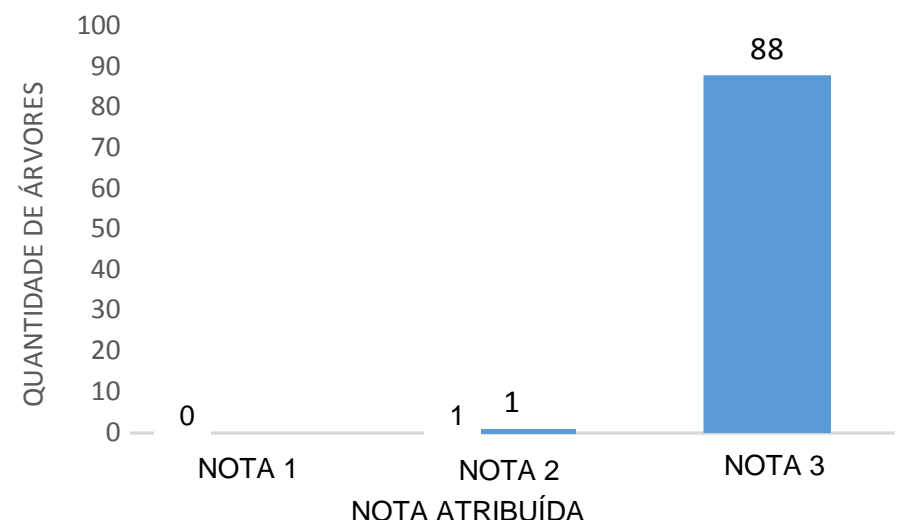

Figura 4. Distribuição dos 89 exemplares arbóreos nas categorias referentes as árvores em contato com a fiação elétrica

Figure 4. Distribution of the 89 arboreal specimens in the categories related to contact with the electrical wiring

Os mais constantes e severos problemas encontrados na arborização urbana em relação ao manejo foram a estrutura inadequada da planta e incompatibilidade com o meio que na maioria das vezes são consequência da proximidade da fiação elétrica, da distância incorreta de postes, plantio sob a fiação nua e/ou plantio de árvores de grande porte que podem vir a entrar em conflito com a rede elétrica, conflito este que é desgastante e de alto custo para as empresas fornecedoras de energia. Além do plantio incorreto o segundo fator determinante é a presença da rede elétrica convencional que não possui fios encapados, facilitando curto circuito na rede, falta de energia e incêndios.

Segundo Ribeiro (2009) o plantio de árvores inadequadas à estrutura urbana gera conflitos com equipamentos urbanos como fiações elétricas, encanamentos, calhas, calçamentos, muros, e postes de iluminação. Estes problemas são muito comuns de serem visualizados e causam, na maioria das vezes, um manejo inadequado e prejudicial às árvores.

Os resultados apresentados na figura 5 demonstram que, quanto a deterioração do tronco, 15 árvores apresentaram danos graves com perfurações e injúrias o que facilita a entrada de patógenos. Esta situação é semelhante a que encontraram Santos et al. (2015), em Aracajú, onde as ações de injúrias foram observadas em 36\% dos indivíduos avaliados, sendo classificadas com base na intensidade da lesão como leves em $24 \%$, médias em $9 \%$ e severas em apenas $3 \%$ das árvores. 


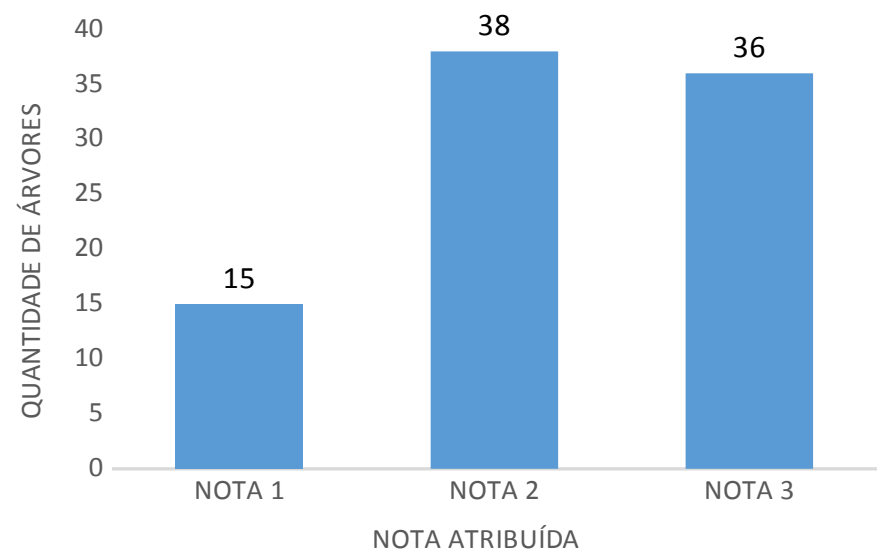

Figura 5. Distribuição dos 89 exemplares arbóreos nas categorias referentes as árvores com deterioração do tronco

Figure 5. Distribution of the 89 tree species in the categories referring to trees with deterioration of the trunk

Quanto a bifurcação do tronco (figura 6), 42 árvores obtiveram nota 3, ou seja, enquadram-se no diagnóstico de bifurcação acima do DAP que garante maior estabilidade. Tal resultado pressupõe uma melhor condução das mesmas através de podas, principalmente naquelas que ainda se encontram em estágio inicial de desenvolvimento, para que estas não venham a apresentar problemas de compatibilidade no futuro.

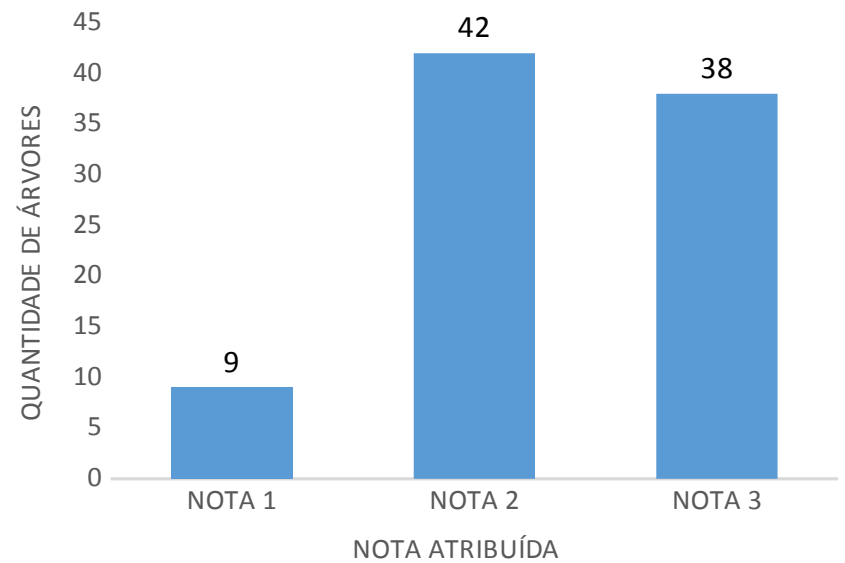

Figura 6. Distribuição dos 89 exemplares arbóreos nas categorias referentes as árvores e a altura da bifurcação

Figure 6. Distribution of the 89 tree species in the categories referring to bifurcation height

A inclinação do tronco é resultado da competição, do espaçamento e da qualidade da muda, essa inclinação dificulta o pleno desenvolvimento da planta além do risco de queda da árvore. $\mathrm{Na}$ análise realizada observou-se que 44 exemplares obtiveram nota 3 e apenas 6 árvores receberam nota 1 que equivale ao tronco inclinado e que apresenta risco de queda (figura 7).

Conforme Almeida e Rondon Neto (2010) a tortuosidade do tronco pode ser proveniente da falta de manejo, problemas na condução e tutoramento da planta em estágio de muda, ou 
ainda, a proximidade das construções às árvores. Além de afetar o acesso aos pedestres e veículos.

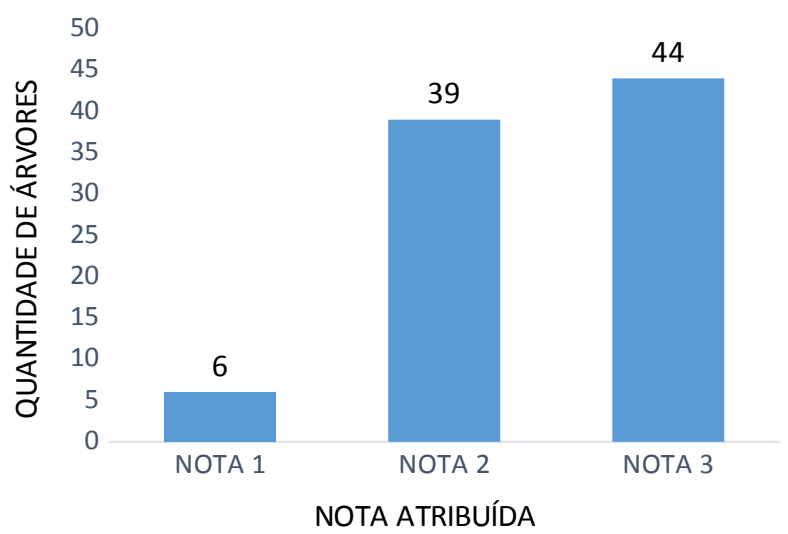

Figura 7. Distribuição dos 89 exemplares arbóreos nas categorias referentes as árvores e nível de inclinação do tronco

Figure 7. Distribution of the 89 tree species in categories related to trunk inclination level

Quanto a presença de hemiparasitas, observa-se através da figura 8 que 57 árvores obtiveram nota 3 , ou seja, possuem menos de $25 \%$ da copa ocupada por hemiparasitas. A ocorrência de hemiparasitas é um resultado comum em avaliação da arborização urbana como cita Santos et al. (2015) em estudo de 25 vias de Aracaju- SE onde também apresentou valor pequeno de exemplares apesar de apenas 1,1\% de um total de 3595 árvores avaliadas, infestadas por parasitas e hemiparasitas. Os autores supracitados alertam ao grande potencial danoso que essas ervas apresentam e que a remoção e o constante monitoramento são necessários, a fim de se evitar essas infestações, que em alguns anos pode ocasionar a morte da planta hospedeira.

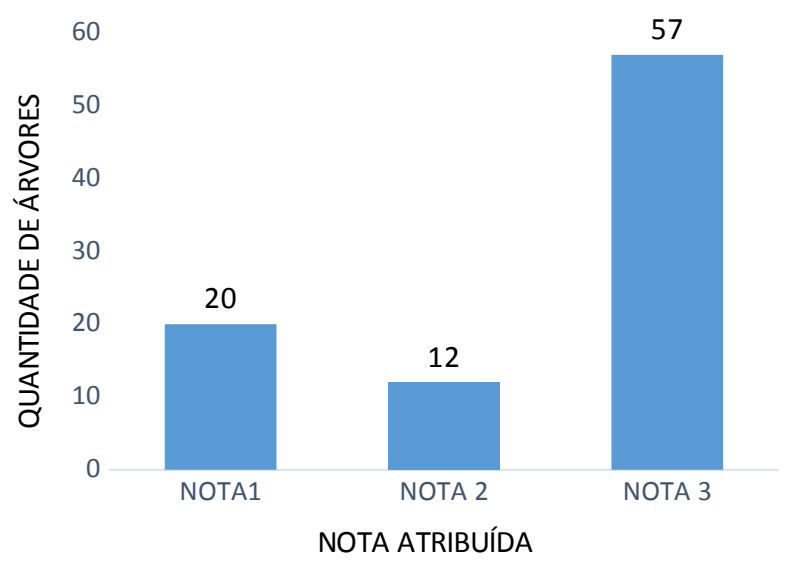

Figura 8. Distribuição dos 89 exemplares arbóreos nas categorias referentes as árvores e a presença de hemiparasitas

Figure 8. Distribution of the 89 tree species in the categories referring to the presence of hemiparasites 
Os resultados apresentados demonstram que, em relação a raízes superficiais a maioria das árvores não apresentaram esse tipo de problema. Esse resultado pode indicar que o plantio foi realizado de forma adequada, que o solo não ofereceu resistência mecânica e diminui a probabilidade de problemas posteriores de rachaduras em calçadas.

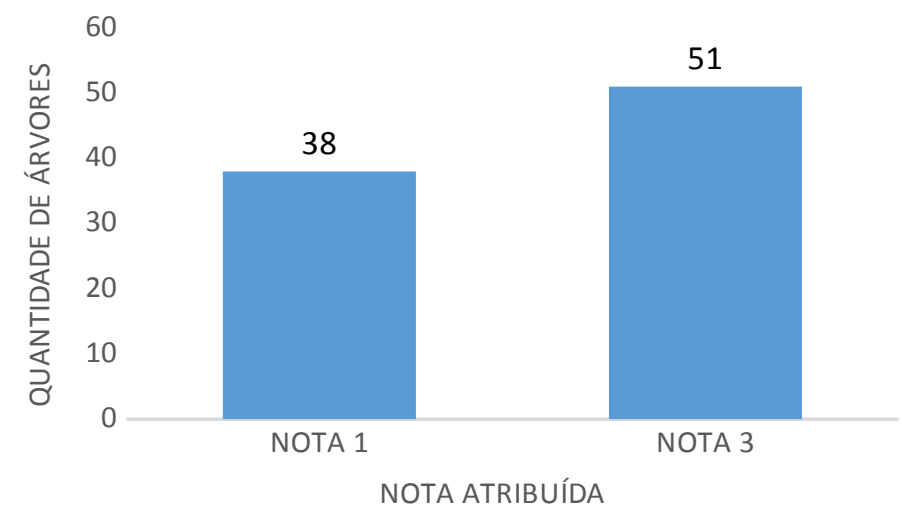

Figura 9. Distribuição dos 89 exemplares arbóreos nas categorias referentes às árvores e ao afloramento de raízes

Figure 9. Distribution of the 89 tree species in the categories related to shallow roots

Em um estudo na cidade de Curitiba - PR, Almeida e Rondon Neto (2010) comentam que a destruição de calçadas por interferência das raízes faz parte do elenco de problemas que dificultam a acessibilidade nos centros urbanos. Esta afirmação é corroborada pelo trabalho de Martelli e Barbosa Júnior (2011) onde constataram que no município de Itapira-SP, no período de janeiro a outubro de 2010 ocorreram 111 supressões de árvores autorizadas e que 10\% delas estavam relacionadas ao fato do sistema radicular estar provocando rachaduras na calçada e entupimento de rede de esgoto.

O fator solo exposto em torno de uma planta caracteriza a cobertura de área livre e ocorre, normalmente devido ao sombreamento e limpeza constante de praças. A área de solo que compreende esse local ficando exposta oportuniza um escorrimento superficial da água sem a percolação da mesma, que além de prejudicar a estabilidade da árvore também afeta a qualidade das raízes e sua distribuição. Na Praça Eufrásio Correia, foram encontrados 40 indivíduos com solo exposto na área livre (figura 10).

Biondi e Althaus (2005) que afirmam que o solo exposto apresenta um ph mais ácido, o que prejudica a ciclagem de nutrientes, que modificam a atividade dos microrganismos, alteram o regime de temperatura e diminuem a disponibilidade de nutrientes para as plantas. Isso promove a perda de vigor das árvores, possibilitando uma maior susceptibilidade a presença de patógenos. A disponibilidade de elementos minerais presentes no solo estimula o crescimento equilibrado das árvores pois apresenta uma solução do solo com melhores condições para a realização das interações solo-planta. 


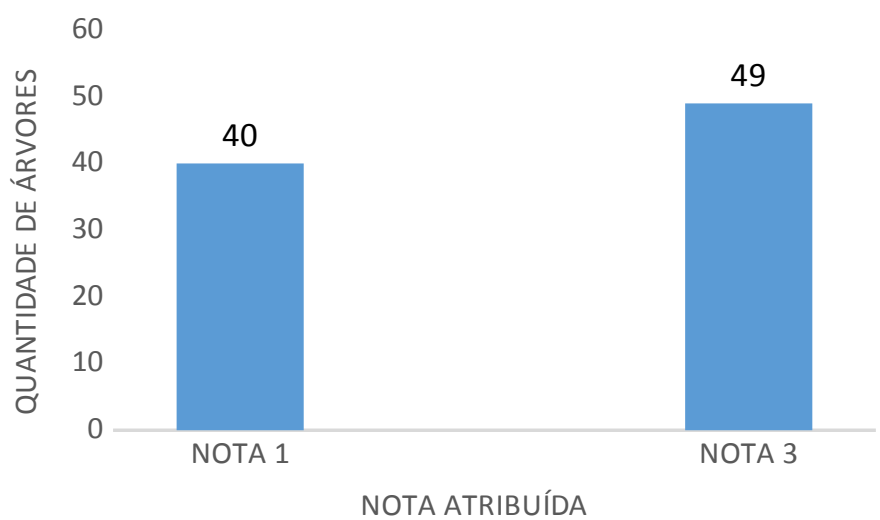

Figura 10. Distribuição dos 89 exemplares arbóreos nas categorias referentes as árvores e ao solo exposto no seu entorno

Figure 10. Distribution of the 89 tree species in the categories referring to the soil exposed in their surroundings

Os resultados na figura 11 demonstram que a maioria dos exemplares não apresenta agentes fitossanitários, são plantas saudáveis em plena fase de desenvolvimento. Este resultado, guardadas as proporções de resultados, é contrário ao trabalho realizado na cidade de Chapadão do Sul no Mato Grosso do Sul, onde no bairro Flamboyant foram 1228 exemplares avaliados e desses $97,72 \%$ das árvores apresentavam agentes fitossanitários (PELEGRIM et el., 2012).

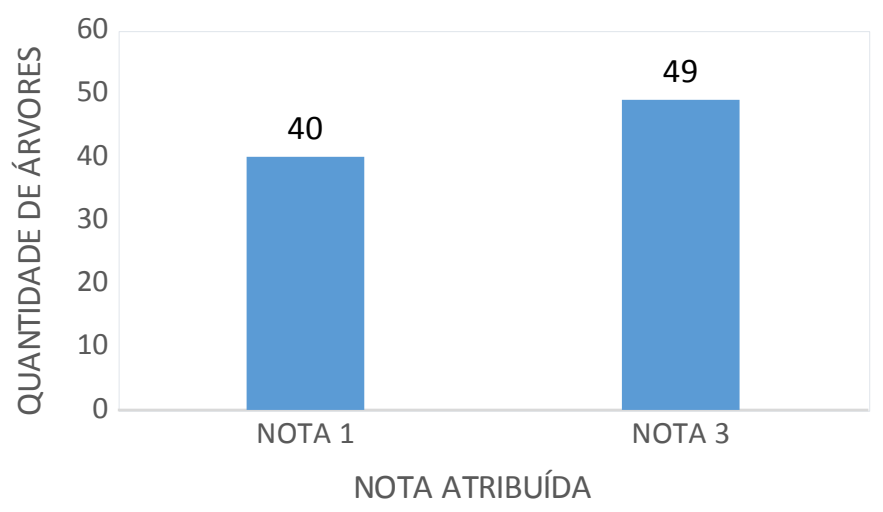

Figura 11. Distribuição dos 89 exemplares arbóreos nas categorias referentes as árvores e a fitossanidade Figure 11. Distribution of the 89 tree species in the categories of plant health

De acordo com o estudo sobre a distância entre a árvore avaliada até o exemplar arbóreo mais próximo compreende-se que 47 árvores de um total de 89 obtiveram nota 2 o que é conseqüência de estar de 2 a 5 metros de distância (tabela 12). Em Irati-PR foi observado de um modo em geral o plantio de indivíduos muito próximos uns aos outros o que resulta em grande competição por radiação solar, água e nutrientes, diminuindo o vigor das plantas, e além de facilitar a propagação de patógenos ou infestantes (SCHALLENBERGER et al., 2010). 


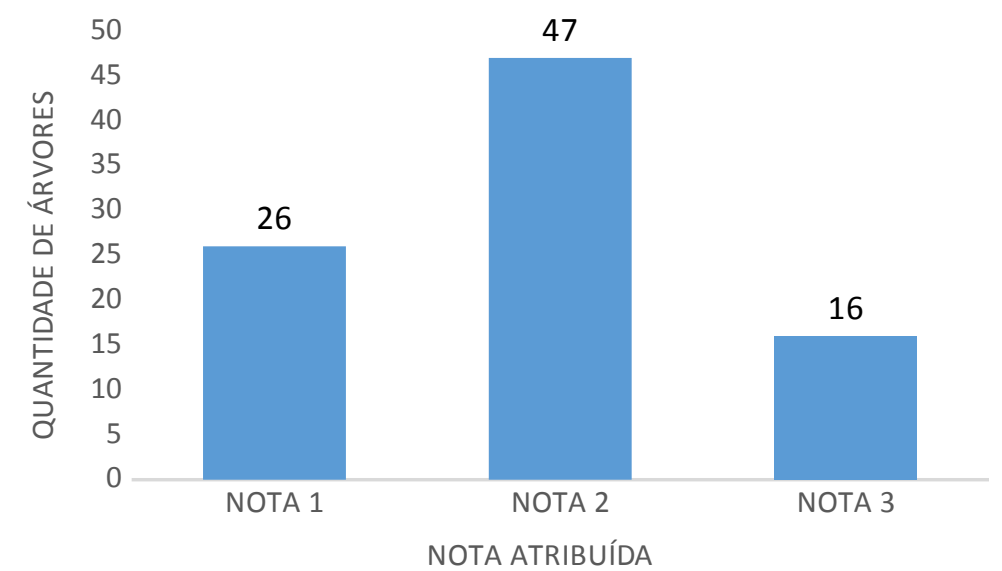

Figura 12. Distribuição dos 89 exemplares arbóreos nas categorias referentes as árvores e a sua distância até a árvore mais próxima

Figure 12. Distribution of the 89 tree species in the categories referring to the trees and their distance to the nearest tree

Quanto a distância até a calçada ou meio fio, observa-se através da figura 13 que a maioria das árvores estava localizada a menos de 2 metros de distância de calçadas ou meio fio, o que caracteriza maior probabilidade de injúrias, vandalismo nos galhos, rachaduras nas calçadas, proximidade de vias e dificultam a acessibilidade e seu respectivo planejamento.

Teixeira, Silva e Tatsch (2011) avaliando a arborização da avenida Celestino Cavalheiro, no Centro de São Gabriel/RS, observaram que 62,26\% dos 134 exemplares inventariados, estão na classe de distância de até $0,30 \mathrm{~m}$ do meio fio.

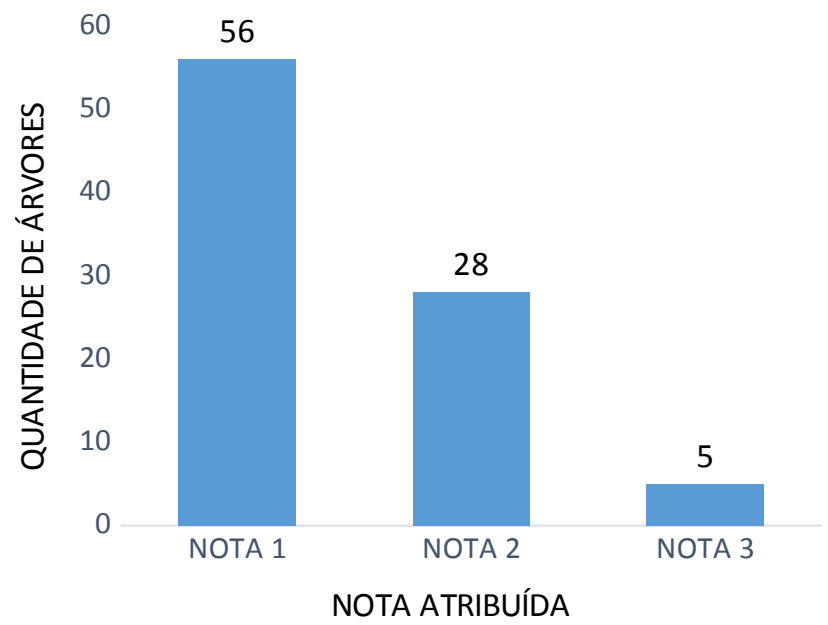

Figura 13. Distribuição dos 89 exemplares arbóreos nas categorias referentes as árvores e a sua distância até a calçada ou meio fio

Figure 13. Distribution of the 89 tree species in the categories referring to the trees and their distance to the sidewalk

Os resultados apresentados na figura 14 demonstram que, quanto a compatibilização com o meio, 37 árvores obtiveram menores resultados, ou seja, são consideradas não 
compatíveis com o meio em que estão alocadas, tendo essa classificação por vários motivos como estar em conflito com outras espécies, com estruturas físicas da praça e/ou com características próprias em desacordo como espécie tóxica, porte, altura ou infestação por patógeno.

Esta incompatibilidade observada também foi analisada por Martelli e Barbosa Junior (2011), em Itapira-SP, ao avaliarem um total de 111 indivíduos arbóreos suprimidos no período de janeiro a outubro de 2010. Desse total, 91 indivíduos foram suprimidos por motivos isolados, sendo 19 deles por problemas como as rachaduras nas calçadas, outros 17 devido as construções e reformas de casas, muros ou mudanças na arquitetura da residência enquanto outros 15 apresentavam o apodrecimento do tronco.

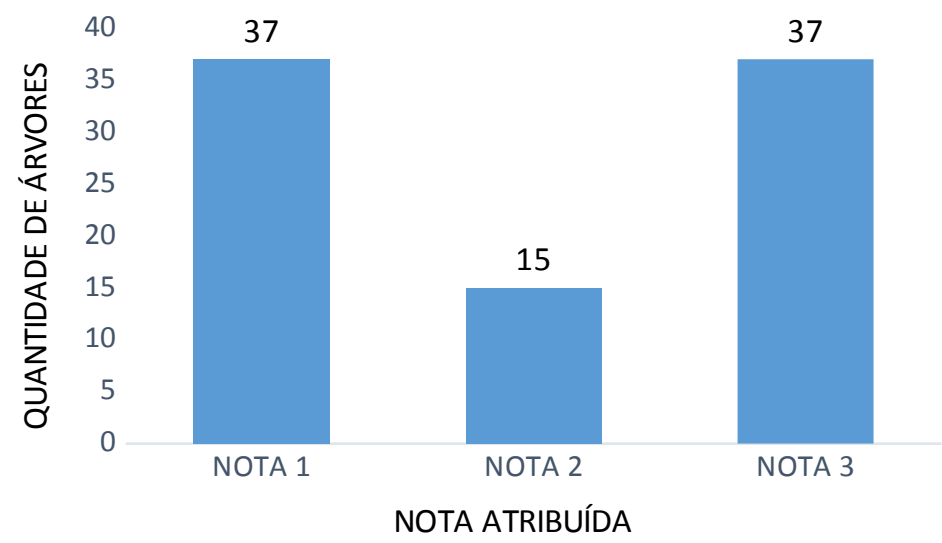

Figura 14. Distribuição dos 89 exemplares arbóreos nas categorias referentes as árvores e a compatibilização com o meio

Figure 14. Distribution of the 89 tree species in the tree categories of environment compatibility

De acordo com os resultados da figura 15, em relação a distância da árvore avaliada até construções ou edificações, a maioria das árvores obtiveram nota 3, ou seja, afastamento maior de 5 metros para construções. A análise desse parâmetro é importante para planejar futuras intervenções como poda, supressão e plantio. Quando se analisa uma praça onde o número de construções é menor pode não apresentar uma relevância como apresentaria na arborização de ruas onde o contato com as estruturas urbanas é sempre imediato necessitando de um manejo mais constante. 


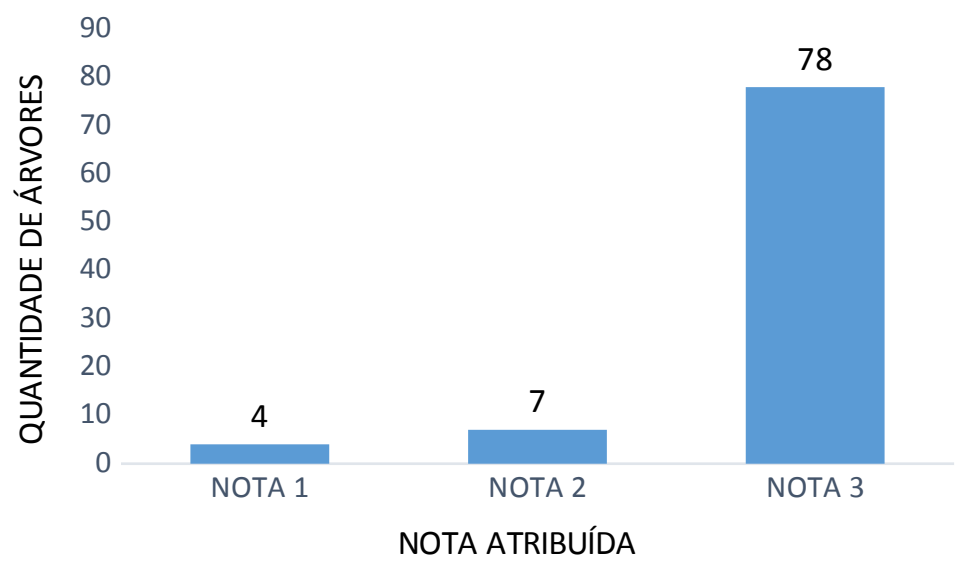

Figura 15. Distribuição dos 89 exemplares arbóreos nas categorias referentes as árvores e a sua distância para construções

Figure 15. Distribution of the 89 tree species in the categories of trees and their distance to buildings

Pesquisas como a de Pretzsch et al. (2015) avaliando espécies comumente usadas na arborização de ruas e em áreas verdes de 9 metrópoles (Sapporo, Japão; Munique Alemanha; Brisbane, Australia; Hanoi, Vietnã. Principe George, Canadá; Paris, França; Cidade do Cabo, África do Sul; Santiago de Chile, Chile), demonstraram a importância do tema de compatibilização pois os referidos autores identificaram a necessidade de estimação dos requisitos espaciais específicos para cada espécie com o objetivo de avaliar benefícios e riscos de incompatibilização nos processos de planejamento urbano.

De acordo com a metodologia empregada, após analisar os parâmetros do diagnóstico da condição dos 89 exemplares arbóreos inventariados da Praça, 15 destas árvores apresentaram condição EXCELENTE, outras 45 foram categorizadas com uma condição BOA, 24 em situação REGULAR e apenas 5 delas em situação péssima (figura 16). A análise final permite que esta praça apresenta em sua maioria exemplares arbóreos em uma condição em que basicamente um controle através de um manejo programado irá manter a sanidade dos mesmo. A categoria péssima, com apenas $5,6 \%$ do total, pressupõe uma análise técnica dos exemplares que conforme o profissional poderá ser um manejo com práticas de tratos silviculturais mais complexos até a supressão, ou seja, a retirada com ou sem reposição.

Em estudos na arborização de uma via na cidade de Dois Vizinhos foram consideradas para supressão $27,2 \%$ do total de 81 exemplares (PEREIRA et al., 2011), usando-se dois métodos de avaliação de risco. Schallenberger et al. (2010) desenvolvendo estudo semiqualitativo da condição da vegetação em seis espaços verdes públicos do município de Irati-PR, onde avaliaram 615 árvores de diferentes espécies, tiveram como resultados 19,35\% classificadas em excelentes, $35,93 \%$ em boas, $32,36 \%$ em regulares, $11,06 \%$ em ruins e $1,3 \%$ se enquadraram na condição péssima. 


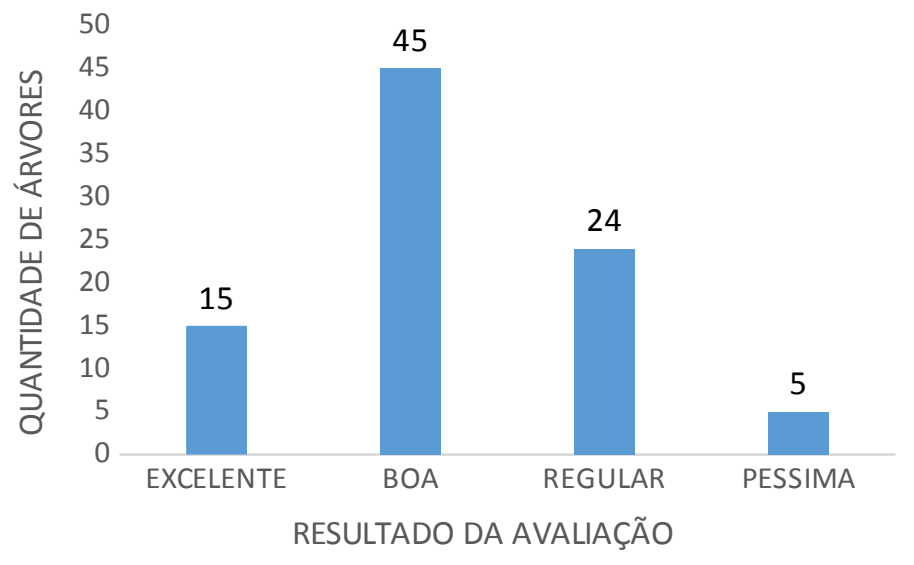

Figura 16. Distribuição dos 89 exemplares arbóreos nas categorias referentes ao resultado da avaliação Figure 16. Distribution of the 89 tree species in the categories related to the evaluation result

\section{CONCLUSÕES}

Em relação a avaliação geral da condição das árvores, $16,85 \%$ do total foram diagnosticadas como excelente, enquanto mais da metade delas apresentaram condição boa. Outros 5\% das árvores foram categorizadas em condição péssima devido aos tratos culturais inadequados como poda, plantio e espaçamento inadequado, presença de hemiparasitas na copa e efeitos de competição que prejudicam o desenvolvimento do indivíduo e representam risco à vida da população e ao patrimônio público, é importante salientar que esses indivíduos necessitam de atenção imediata para que essas características não potencializem os riscos.

Além dessas, outros $26,96 \%$ das árvores foram categorizadas em condição regular, as quais necessitam da aplicação de um manejo adequado para estimular suas atividades fisiológicas e recuperar o vigor.

Por meio da análise dos resultados obtidos nesse estudo pode-se concluir que a metodologia utilizada é eficiente e prática na análise expedita da condição da arborização, possibilitando a obtenção de informações visando fomentar um banco de dados ou um processo comparativo com outros métodos semelhantes. No entanto é importante salientar que esta metodologia gera informações de caráter empírico e subjetivo o que pode limitar a sua eficiência. 


\section{REFERÊNCIAS}

ALMEIDA, D. N.; RONDON NETO, R. M. Análise da Arborização Urbana de Três Cidades da Região Norte do Estado de Mato Grosso. Acta Amazônica, Manaus, v. 40, n. 4, p. 647-656, 2010.

BIONDI, D.; ALTHAUS, M. Árvores de rua de Curitiba: cultivo e manejo. Curitiba: FUPEF, 2005. $179 \mathrm{p}$.

BRAZOLIN, S.; TOMAZELLO FILHO, M.; YOJO, T.; OLIVEIRA NETO, N. A.; ALBUQUERQUE, A. R.; SETTE JÚNIOR. C. R. Propriedades físico-mecânicas do lenho deteriorado por fungos apodrecedores de árvores de Tipuana tipu. Cerne, Lavras, v.20, n.2, p.183-190, 2014.

GONÇALVES, W; STRINGHETA, A.C.O.; COELHO, L.L. Análise de árvores urbanas para fins de supressão. Revista da Sociedade Brasileira de Arborização Urbana, Piracicaba, v.2, n.4, p. 1-19, dez. 2007.

IPPUC - INSTITUTO DE PESQUISA E PLANEJAMENTO URBANO DE CURITIBA Desenvolvimento sustentável: indicadores de sustentabilidade de Curitiba - 2010. Curitiba: IPPUC, 2013.

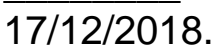

Curitiba em dados. 2011.Disponível em: <http://goo.gl/4IZHZg>. Acesso em:

KONTOGIANNI, A.; TSITSONI, T.; GOUDELIS, G. An index based on silvicultural knowledge for tree stability assessment and improved ecological function in urban ecosystems. Ecological

Engineering, Amsterdam, v.37, n.6, p.914-919, 2011.

MARTELLI, A.; BARBOSA JR., J. Incidência e fatores causais das supressões da arborização urbana no município de Itapira, Estado de São Paulo. Revista Acadêmica: Ciências Agrárias e Ambientais, Curitiba, v. 9, n. 2, p. 215-222. 2011.

MARTINS, L. F. V.; ANDRADE, H.H.B.DE; DE ANGELIS, B.L.D. Relação entre podas e aspectos fitossanitários em árvores urbanas na cidade de Luiziana, PR. Revista da Sociedade Brasileira de Arborização Urbana, Piracicaba, v.5, n.4, p.141-155, 2010.

MASCARÓ, L., MASCARÓ, J. L. Vegetação urbana. 3aㅗ ed. Porto Alegre: Masquatro Editora; 2010. 212 p.

PELEGRIM, E.A.L. Avaliação qualitativa e quantitativa da arborização no bairro Flamboyant em Chapadão do Sul, MS. Revista da Sociedade Brasileira de Arborização Urbana, Piracicaba, v.7, n.1, p. 126-142, 2012

PEREIRA, P.H., TOPANOTTI, L.R., DALLACORT, S., MOTA, C.J.DA, BRUN, F.G.K., SILVA, R.T.L. Estudo de caso do risco de queda de árvores urbanas em via pública na cidade de Dois Vizinhos-PR. Synergismus scyentifica, Pato Branco ,v.6, n.1, p.1-10, 2011.

PRETZSCH, H., BIBER, P., UHL, E., DAHLHAUSEN, J., RÖTZER, T., CALDENTEY, J., KOIKEC, T., VAN COND, T., CHAVANNEE, A., SEIFERTF, T., DU TOITF, B. , FARNDENG, C., PAULEIT, S. Crown size and growing space requirement of common tree species in urban centers, parks, and forests. Urban Forestry \& Urban Greening, Amsterdam, v.14,n.3, p. 466479,2015 
RIBEIRO, F. A. B. S. Arborização Urbana em Uberlândia: percepção da população. Revista da Católica, Uberlândia, v. 1, n. 1, p. 224-237, 2009.

SALBITANO, F., BORELLI, S., CONIGLIARO, M. CHEN, Y. Directrices para la silvicultura urbana y periurbana. Roma: Estudio FAO, 191 p. 2017.

SAMPAIO, A. C. F., DUARTE, F.G., SILVA, E.G.C., DE ANGELIS, B.L.D., BLUM, C.T. Avaliação de árvores de risco na arborização de vias públicas de Nova Olímpia, Paraná. Revista da Sociedade Brasileira de Arborização Urbana, Piracicaba, v.5, n.2, p.82-104, 2010.

SANTOS, C. Z. A.; FERREIRA, R.A.; SANTOS, L.R.; SANTOS, L.I.; GOMES, S.H.; DA GRAÇA, D.A.S. Análise qualitativa da arborização urbana de 25 vias públicas da cidade de Aracaju-SE. Ciência Florestal, Santa Maria, v. 25, n. 3,p.751-763, 2015.

SCHALLENBERGER, L.S., ARAÚJO, A.J.DE, ARAUJO, M.N.DE, DEINER, L.J., MACHADO, G.DE O.Avaliação da condição de árvores urbanas nos principais parques e praças do município de Irati-PR. Revista da Sociedade Brasileira de Arborização Urbana, Piracicaba, v.5, n.2, p.105-123, 2010.

TEIXEIRA, I.F.; SILVA, R.M.; TATSCH, G.L. Compatibilidade da arborização de ruas da Avenida Celestino Cavalheiro, São Gabriel-RS. Floresta e Ambiente, Rio de Janeiro, v.4, n.18, p. 438450, 2011. 